\title{
Analiza ryzyka zgonu z powodu ogółu przyczyn oraz z powodu COVID-19 osób zaszczepionych i niezaszczepionych przeciw COVID-19
}

dr n. przyr. Bogdan Wojtyniak, prof. NIZP PZH - PIB dr n. med. Daniel Rabczenko dr hab. n. o zdr. Grzegorz Juszczyk 


\section{NARODOWY INSTYTUT ZDROWIA PUBLICZNEGO PZH \\ - PAŃSTWOWY INSTYTUT BADAWCZY}

(C) Copyright by Narodowy Instytut Zdrowia Publicznego PZH - Państwowy Instytut Badawczy, 2021 Przedruk materiałów w całości lub części jest możliwy wyłącznie za zgodą Narodowego Instytutu Zdrowia Publicznego PZH - Państwowego Instytutu Badawczego.

Cytowanie i wykorzystanie danych empirycznych dozwolone za podaniem źródła.

doi 10.32394/niph.001

Autorzy:

dr n. przyr. Bogdan Wojtyniak, prof. NIZP PZH - PIB

dr n. med. Daniel Rabczenko

dr hab. n. o zdr. Grzegorz Juszczyk

Opracowanie graficzne i skład:

Marta Kaczanowska 
Spis treści

Opis przeprowadzonych analiz ......................................................... 4

Wyniki .................................................................................... 7

Umieralność ogółem............................................................. 9

Umieralność z powodu COVID-19 ..................................................... 9

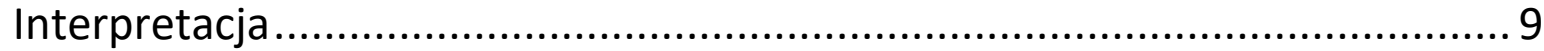




\section{Opis przeprowadzonych analiz}

Analizę ryzyka zgonu osób zaszczepionych i nieszczepionych przeciw COVID-19 przeprowadzono z wykorzystaniem zbiorów danych otrzymanych z Departamentu Analiz i Strategii Ministerstwa Zdrowia (DAiS). Pierwszy zbiór zawierał informacje o zgonach wszystkich osób w okresie od 1 stycznia 2021 do 10 października 2021 r. wraz z datą zgonu, datą ewentualnego zaszczepienia (status zaszczepienia - zmienna dawka: druga dawka, pierwsza J\&J, bez szczepienia oraz zmienna data dawka z datą zaszczepienia) oraz wiekiem w ukończonych latach. Drugi zbiór zawierał informacje o wszystkich osobach zaszczepionych i dacie ich szczepienia. Dzięki unikalnemu zanonimizowanemu identyfikatorowi obydwa zbiory zostały połączone co pozwoliło na określenie statusu przeżycia osób zaszczepionych i nieszczepionych. Ze względu na różną długość obserwacji poszczególnych osób w grupie zaszczepionych oraz inną długość obserwacji osób nieszczepionych w celu obliczenia ryzyka zgonu osób w każdej grupie konieczne było policzenie osobodni obserwacji. Analizę prowadzono dla osób w 10-letnich grupach wieku, dla których obliczone zostało ryzyko zgonu osób zaszczepionych i nieszczepionych. Liczono je dzieląc liczbę zgonów przez liczbę osobodni ${ }^{1}$, które przypadają na osoby w populacji zaszczepionej i nieszczepionej.

W obliczeniach przyjęto następujące założenia:

- Osobodni obserwacji osób niezaszczepionych zmarłych z powodu ogółu przyczyn obliczono według wzoru:

$O_{N Z}=\left\{\begin{array}{l}\text { liczba dni pomiędzy 19.01.2021 a 10.10.2021 (264 dni) } \\ \text { liczba dni pomiedzy 19.01.2021 a datą zgonu }\end{array}\right.$

gdzie 19.01.2021 to data pierwszego zaszczepienia drugą dawką osób w grupie szczepionej

- Osobodni obserwacji osób zaszczepionych zmarłych z powodu ogółu przyczyn obliczono według wzoru:

$O_{Z}=\left\{\begin{array}{l}\text { liczba dni pomiędzy datą zaszczepienia a } 10.10 .2021 \\ \text { liczba dni pomiedzy datą zaszczepienia a datą zgonu }\end{array}\right.$

- Osobodni obserwacji osób niezaszczepionych zmarłych z powodu COVID-19 obliczono według wzoru:

liczba dni pomiędzy 19.01.2021 a 10.10.2021 (264 dni)

$O_{Z}=\{$ liczba dni pomiedzy 19.01.2021 a datą zgonu liczba dni pomiedzy pomiędzy 19.01.2021 a datą zgonu z innego powodu

- Osobodni obserwacji osób zaszczepionych zmarłych z powodu COVID-19 obliczono według wzoru:

liczba dni pomiędzy datą zaszczepienia a 10.10.2021

$O_{Z}=\{$ liczba dni pomiedzy datą zaczepienia a datą zgonu z powodu COVID liczba dni pomiedzy datą zaszczepienia a datą zgonu z innego powodu

\footnotetext{
${ }^{1} 1$ osobodzień = 1 osoba, która przeżyła w okresie objętym obserwacją 1 dzień
} 
Schemat analizy ryzyka zgonu z powodu ogółu przyczyn oraz z powodu COVID-19 osób zaszczepionych i nieszczepionych przeciw COVID-19 został przedstawiony na poniższych rycinach 1 i 2.

Rycina 1: Schemat analizy dla szacowania ryzyka względnego zgonu z powodu ogółu przyczyn osób zaszczepionych i niezaszczepionych

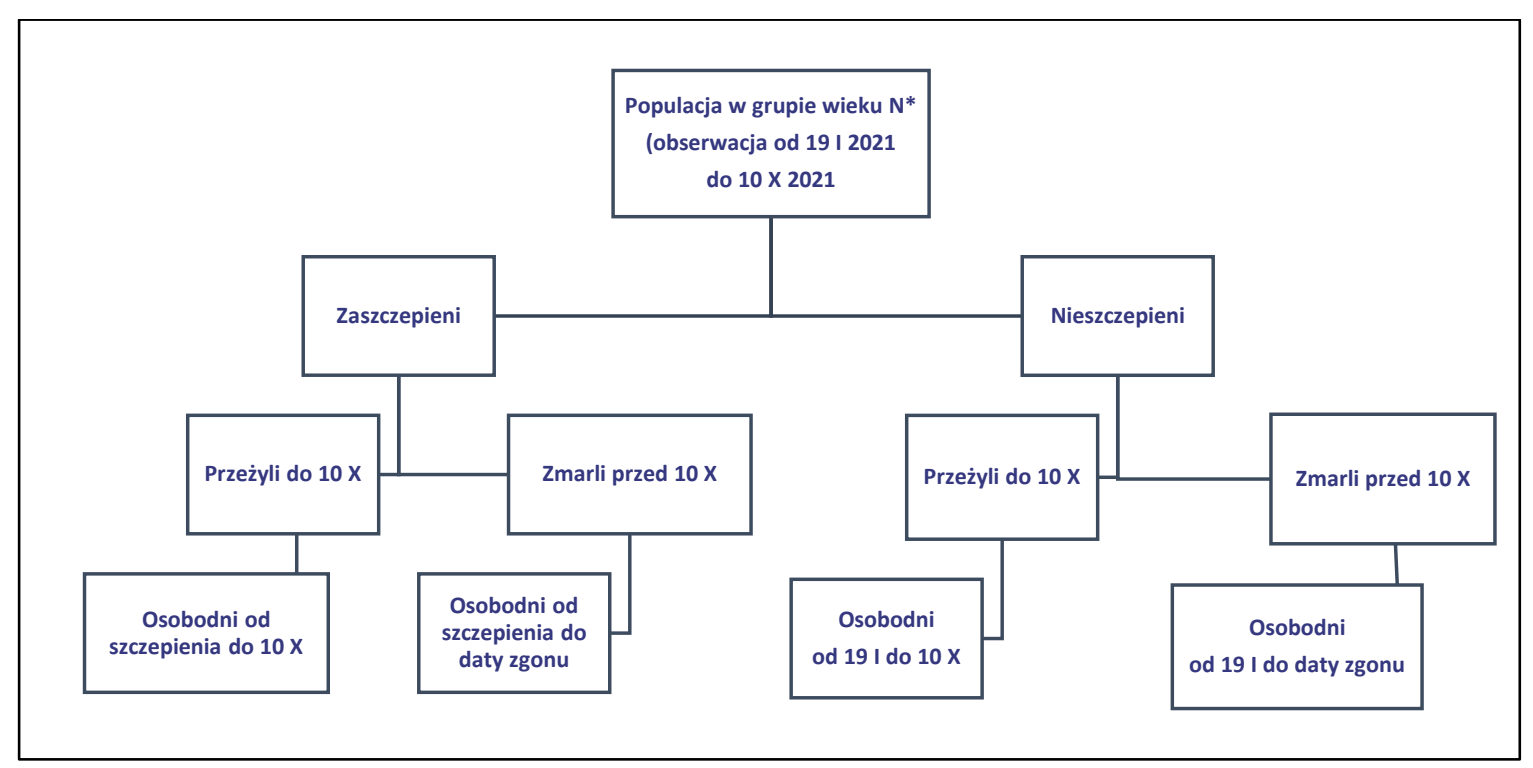

*rozważano grupy wieku zdefiniowane przez DAiS : 11-20, 21-30, 31-40, 51-60, 61-70, 71-80, 81 i więcej lat 
Rycina 2: Schemat analizy dla szacowania ryzyka względnego zgonu z powodu COVID-19 osób zaszczepionych i niezaszczepionych

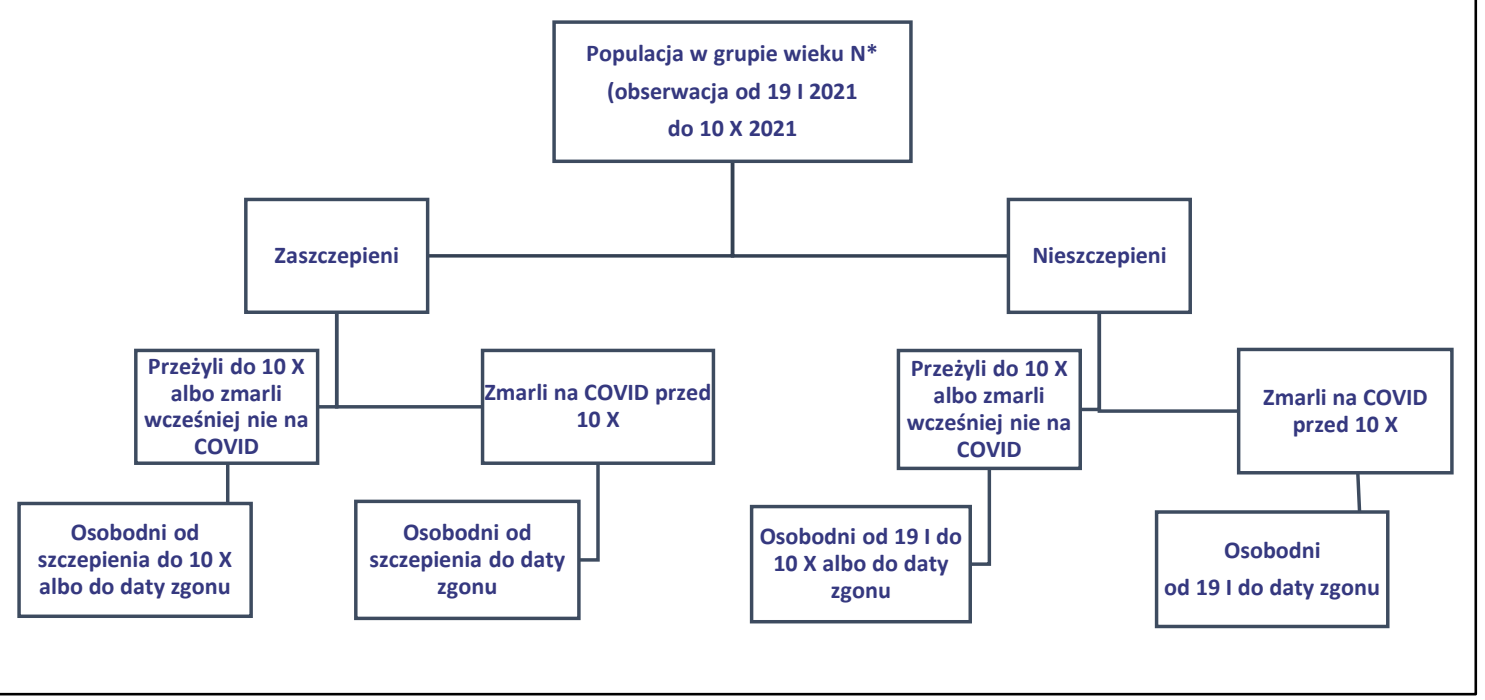

*rozważano grupy wieku zdefiniowane przez DAiS : 11-20, 21-30, 31-40, 51-60, 61-70, 71-80, 81 i więcej lat

Ryzyko względne zalicza się do podstawowych miar związku między narażeniem na dany czynnik ryzyka zdarzenia zdrowotnego, albo temu zdarzeniu zapobiegający, a wystąpieniem tego zdarzenia. W przypadku prezentowanej analizy takim zdarzeniem zdrowotnym jest zgon a czynnikiem, który ma mu ewentualnie zapobiegać jest zaszczepienie. Ryzyko względne to iloraz ryzyka zgonu w grupie osób niezaszczepionych i ryzyka zgonu w grupie zaszczepionych (Rosińska M., Rabczenko D., Wojtyniak B.: Podstawowe miary epidemiologiczne rozpowszechnienia, przebiegu i ciężkości chorób, w: Paradowska-Stankiewicz I., Rosińska M., Wojtyniak B., Zieliński A. (red.), EPIDEMIOLOGIA Od teorii do praktyki, PZWL, Warszawa 2021). 


\section{Wyniki}

\section{Tabela 1. Zgony z powodu ogółu przyczyn}

\begin{tabular}{|c|c|c|c|c|c|c|c|c|c|c|c|c|c|}
\hline \multirow[b]{2}{*}{$\begin{array}{l}\frac{3}{0} \\
\frac{0}{3} \\
\frac{\pi}{3} \\
\frac{0}{3} \\
\frac{1}{0}\end{array}$} & \multicolumn{3}{|c|}{ Ludność } & \multicolumn{2}{|c|}{ Osobodni do zgonu } & \multicolumn{2}{|c|}{ Zgony } & \multirow{2}{*}{$\begin{array}{c}\text { Czas od } \\
\text { zaszczepienia } \\
\text { osób, które } \\
\text { żyją }\end{array}$} & \multicolumn{2}{|c|}{ Osobodni - mianownik } & \multicolumn{2}{|c|}{$\begin{array}{c}\text { Ryzyko zgonu/1000 } \\
\text { osobodni }\end{array}$} & \multirow[t]{2}{*}{$\begin{array}{l}\text { Ryzyko } \\
\text { względne }\end{array}$} \\
\hline & $\frac{\varepsilon}{0}$ & 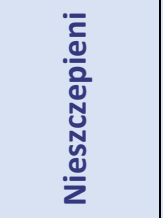 & 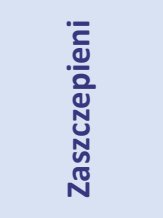 & 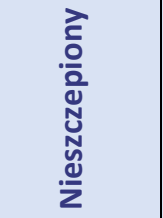 & $\begin{array}{l}\text { ते } \\
\frac{0}{0} \\
\text { N } \\
\text { N }\end{array}$ & 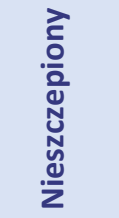 & 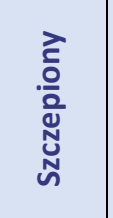 & & 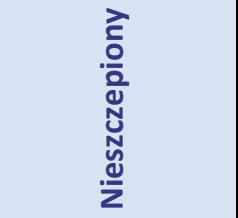 & 흘 & 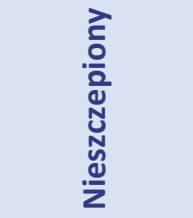 & $\begin{array}{l}\text { בे } \\
\stackrel{0}{0} \\
\text { N } \\
\text { N }\end{array}$ & \\
\hline 1 & 2 & 3 & 4 & 5 & 6 & 7 & 8 & 9 & $\begin{array}{r}{[10]=} \\
([3]-[7]) * 264+[5]\end{array}$ & $\begin{array}{r}{[11]=} \\
{[6]+[9]}\end{array}$ & $\begin{array}{r}{[12]=} \\
{[7] /[10]^{*} 1000}\end{array}$ & $\begin{array}{c}{[13]=} \\
{[8] /[11]^{*} 1000}\end{array}$ & {$[12] /[13]$} \\
\hline $11-20$ lat & 3820360 & 3309427 & 510933 & 91843 & 2624 & 670 & 55 & 102884961 & 873603691 & 102887585 & 0,0008 & 0,0005 & 1,4347 \\
\hline $21-30$ lat & 4538409 & 3117084 & 1421325 & 261295 & 13519 & 2007 & 212 & 213222399 & 822641623 & 213235918 & 0,0024 & 0,0010 & 2,4539 \\
\hline $31-40$ lat & 6136673 & 3972347 & 2164326 & 707516 & 37776 & 5565 & 537 & 320097183 & 1047937964 & 320134959 & 0,0053 & 0,0017 & 3,1658 \\
\hline $41-50$ lat & 5615393 & 3007647 & 2607746 & 1452253 & 108394 & 11929 & 1509 & 386527562 & 792321805 & 386635956 & 0,0151 & 0,0039 & 3,8576 \\
\hline $51-60$ lat & 4632003 & 2266164 & 2365839 & 2848926 & 280090 & 24280 & 3714 & 361210493 & 594706302 & 361490583 & 0,0408 & 0,0103 & 3,9738 \\
\hline $61-70$ lat & 5120490 & 1873219 & 3247271 & 7290417 & 1001488 & 65492 & 12760 & 470693591 & 484530345 & 471695079 & 0,1352 & 0,0271 & 4,9966 \\
\hline $71-80$ lat & 2683598 & 647148 & 2036450 & 7292835 & 1881390 & 69785 & 20147 & 350169219 & 159716667 & 352050609 & 0,4369 & 0,0572 & 7,6350 \\
\hline Pow. 80 lat & 1490690 & 554823 & 935867 & 13062009 & 3800993 & 118656 & 34672 & 184781496 & 128210097 & 188582489 & 0,9255 & 0,1839 & 5,0337 \\
\hline Razem & 34037616 & 18747859 & 15289757 & 33007094 & 7126274 & 298384 & 73606 & 2389586904 & 4903668494 & 2396713178 & 0,0608 & 0,0307 & 1,9813 \\
\hline
\end{tabular}


Tabela 2. Zgony z powodu COVID-19

\begin{tabular}{|c|c|c|c|c|c|c|c|c|c|c|c|c|c|}
\hline \multirow[b]{2}{*}{$\begin{array}{l}\frac{2}{0} \\
\frac{0}{3} \\
\frac{0}{3} \\
\frac{0}{3} \\
00\end{array}$} & \multicolumn{3}{|c|}{ Ludność } & \multicolumn{2}{|c|}{ Osobodni do zgonu } & \multicolumn{2}{|c|}{ Zgony } & \multirow{2}{*}{$\begin{array}{c}\text { Czas od } \\
\text { zaszczepienia } \\
\text { osób, które } \\
\text { żyją }\end{array}$} & \multicolumn{2}{|c|}{ Osobodni - mianownik } & \multicolumn{2}{|c|}{$\begin{array}{c}\text { Ryzyko zgonu/1000 } \\
\text { osobodni }\end{array}$} & \multirow[t]{2}{*}{$\begin{array}{c}\text { Ryzyko } \\
\text { względne }\end{array}$} \\
\hline & $\frac{\varepsilon}{\frac{\varepsilon}{0}}$ & $\begin{array}{l}\bar{c} \\
\frac{\bar{d}}{0} \\
\frac{0}{N} \\
\frac{N}{2} \\
\frac{d}{z}\end{array}$ & 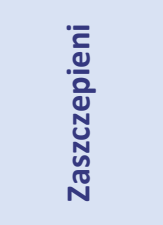 & 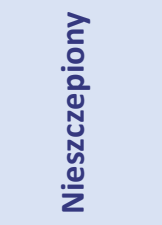 & đั & 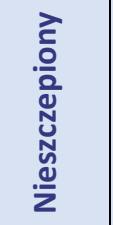 & 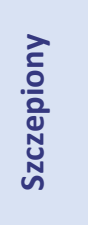 & & $\begin{array}{l}\text { ¿̀ } \\
\frac{0}{0} \\
\frac{0}{2} \\
\text { N } \\
\frac{\tilde{d}}{z}\end{array}$ & 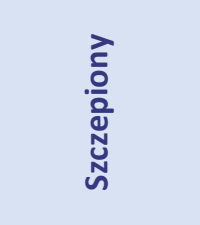 & $\begin{array}{l}\text { ¿े } \\
\frac{0}{0} \\
\stackrel{N}{N} \\
\frac{\tilde{d}}{z}\end{array}$ & 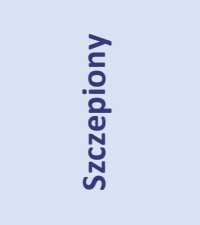 & \\
\hline 1 & 2 & 3 & 4 & 5 & 6 & 7 & 8 & 9 & $\begin{array}{r}{[10]=} \\
([3]-[7]) * 264+[5]\end{array}$ & $\begin{array}{r}{[11]=} \\
{[6]+[9]}\end{array}$ & $\begin{array}{r}{[12]=} \\
{[7] /[10]^{*} 1000}\end{array}$ & $\begin{array}{r}{[13]=} \\
{[8] /[11]^{*} 1000}\end{array}$ & {$[12] /[13]$} \\
\hline $11-20$ lat & 3820360 & 3309427 & 510933 & 91843 & 0 & 12 & 0 & 102890741 & 873777403 & 102890741 & 0,0000 & 0,0000 & - \\
\hline $21-30$ lat & 4538409 & 3117084 & 1421325 & 261295 & 0 & 98 & 0 & 213250718 & 823145599 & 213250718 & 0,0001 & 0,0000 & - \\
\hline $31-40$ lat & 6136673 & 3972347 & 2164326 & 707516 & 458 & 351 & 5 & 320167150 & 1049314460 & 320167608 & 0,0003 & 0,0000 & 21,4195 \\
\hline 41-50 lat & 5615393 & 3007647 & 2607746 & 1452253 & 324 & 1026 & 8 & 386730636 & 795200197 & 386730960 & 0,0013 & 0,0000 & 62,3720 \\
\hline $51-60$ lat & 4632003 & 2266164 & 2365839 & 2848926 & 725 & 2614 & 13 & 361737362 & 600426126 & 361738087 & 0,0044 & 0,0000 & 121,1426 \\
\hline $61-70$ lat & 5120490 & 1873219 & 3247271 & 7290417 & 5500 & 10269 & 70 & 472577744 & 499109217 & 472583244 & 0,0206 & 0,0001 & 138,9034 \\
\hline $71-80$ lat & 2683598 & 647148 & 2036450 & 7292835 & 13915 & 12969 & 208 & 353562626 & 174716091 & 353576541 & 0,0742 & 0,0006 & 126,1809 \\
\hline Pow. 80 lat & 1490690 & 554823 & 935867 & 13062009 & 32719 & 14360 & 583 & 191446284 & 155744241 & 191479003 & 0,0922 & 0,0030 & 30,2827 \\
\hline Razem & 34037616 & 18747859 & 15289757 & 33007094 & 53641 & 41699 & 887 & 2402363261 & 4971433334 & 2402416902 & 0,00839 & 0,00037 & 22,718 \\
\hline
\end{tabular}




\section{Umieralność ogółem}

Uzyskane wyniki wskazują na znacznie większe ryzyko zgonu z powodu ogółu przyczyn osób niezaszczepionych w stosunku do zaszczepionych przeciwko COVID-19 we wszystkich grupach wieku (Tabela 1). Ryzyko względne zgonu dla całej populacji osób niezaszczepionych w wieku 11 lat i więcej w stosunku do osób zaszczepionych w analizowanym okresie wynosiło 1,981 (95\% C.I. 1,965 - 1,997). Ryzyko względne różniło się istotnie w grupach wieku i po uwzględnieniu różnic w strukturze wieku w obu grupach (Mantel-Haenszel adjusted Rate Ratio) ryzyko zgonu w całej populacji niezaszczepionych w stosunku do zaszczepionych wyniosło 5,395 (95\% C.I. 5,351-5,438).

\section{Umieralność z powodu COVID-19}

W kolejnym kroku policzono ryzyko zgonu wyłącznie z powodu COVID-19, aczkolwiek trzeba pamiętać, że liczba zgonów z powodu COVID-19 może być na obecnym etapie zbierania danych niedoszacowana.

Uzyskane wyniki wskazują na wielokrotnie większe niż w przypadku ogółu zgonów ryzyko zgonów z powodu COVID-19 osób niezaszczepionych w stosunku do zaszczepionych przeciwko COVID-19 (Tabela 2). Ryzyko względne zgonu dla całej populacji osób niezaszczepionych w wieku 11 lat i więcej w stosunku do osób zaszczepionych w analizowanym okresie wynosiło 22,72 (95\% C.I. 21,26 - 24,28). Ryzyko względne różniło się istotnie w grupach wieku i po uwzględnieniu różnic w strukturze wieku w obu grupach (Mantel-Haenszel adjusted Rate Ratio) ryzyko zgonu w całej analizowanej populacji niezaszczepionych w stosunku do zaszczepionych wyniosło 59,92 (95\% C.I. 56,08-64,03).

\section{Interpretacja}

Interpretując uzyskane wyniki należy pamiętać, że pochodzą one z badania obserwacyjnego i przydział osób do grupy szczepionej i nieszczepionej nie był losowy (randomizowany). Jest prawdopodobne, że osoby, które się zaszczepiają i osoby nie zaszczepiające się różnią się pod względem stanu zdrowia albo występowania innych czynników ryzyka zdrowotnego (na przykład behawioralnych). Z tego względu nie można interpretować uzyskanych wyników jako mierzących efektywność szczepionek. Wyniki te można traktować jako przybliżoną miarę korzyści zdrowotnej (mierzonej brakiem zgonu) jaką osiąga populacja osób zaszczepionych w porównaniu z osobami niezaszczepionymi. Niewątpliwie bardzo potrzebne jest określenie na podstawie danych NFZ faktu leczenia się z powodu wybranych chorób (występowania wielochorobowości) przez osoby w obu porównywanych grupach oraz faktu wcześniejszego chorowania na COVID-19, co będzie przedmiotem kolejnej analizy. 


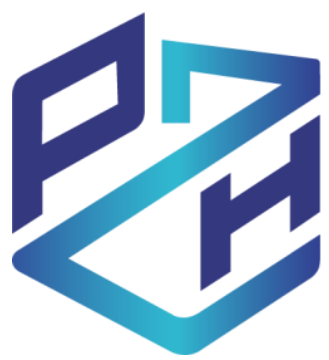

NARODOWY

INSTYTUT

ZDROWIA

PUBLICZNEGO

PAŃSTWOWY INSTYTUT

BADAWCZY

Narodowy Instytut Zdrowia Publicznego PZH - Państwowy Instytut Badawczy

ul. Chocimska 24, 00-791 Warszawa

tel. +48225421 400, +48225421200

e-mail: wydawnictwo@pzh.gov.pl

www.pzh.gov.pl 